\title{
ASSESSMENT OF THE DAMAGE FOR THE HEALTH OF THE POPULATION FROM THE SHORT-TERM EXPOSURE TO THE HIGH OZONE CONCENTRATIONS
}

\section{Turos O.I., Petrosian A.A., Maremukha T.P. ОЦПНКА ЗБИТКІВ ЗДОРОВ'|І НАСЕЛЕННЯ ВІД КОРОТКОЧАСНОГО ВПЛИВУ ВИСОКИХ КОНЦЕНТРАЦИЙ ОЗОНУ}

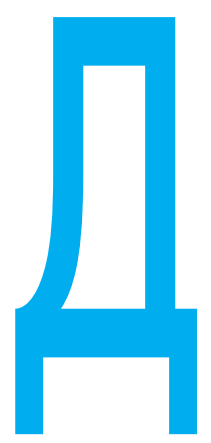

TYPOC 0.I. ПЕТРОСЯН А.А. , MAPEMУХА Т.П.

ДУ «Інститут громадського здоров'я ім. О.М. Марзєєва НАМН України», м. Київ, Україна о потенційно небезпечних забруднюючих речовин, про негативний вплив яких на здоров'я населення отримані достатні докази, належить озон [1-3]. Небезпечні концентрації озону утворюються за несприятливих метеорологічних умов (передусім за відсутності вітру та температур повітря вище $27^{\circ} \mathrm{C}$ ). Зміни клімату та відсутність тенденції до зниження забруднення атмосферного повітря оксидами азоту і вуглецю, леткими органічними сполуками (ЛОС) тощо призводять у результаті фотохімічних реакцій до утворення приземного озону під впливом сонячного випромінювання. Нині спостерігається зростання рівня концентрації озону у приземному шарі атмосфери, що є причиною підвищення дози впливу та, відповідно, ризиків для здоров'я населення $[2,4]$.

За даними звіту «State of global air», майже 97-98\% населення Європи перебуває під експозицією високих рівнів концентрацій озону [5], що $є$ причиною 234,0 тисяч додаткових смертей від хронічних захворювань легень. Численні епідеміологічні дослідження 3 оцінки впливу приземного озону у США i розвинених країнах Європи проводяться вже кілька десятиліть. Зокрема, у роботі Bates D.V. відзначається, що отримані результати мають настільки вичерпний характер, що за кількістю викликів
ОЦІНКА ЗБИТКІВ ЗДОРОВ'Ю НАСЕЛЕННЯ ВІД КОРОТКОЧАСНОГО ВПЛИВУ ВИСОКИХ КОНЦЕНТРАЦІЙ ОЗОНУ

Турос О.І., Петросян А.А., Маремуха Т.П. ДУ «Інститут громадського здоров'я ім. О.М. Марзєєва НАМН України», м. Київ, Україна

Мета: визначення та аналіз отриманих концентрацій озону в атмосферному повітрі м. Києва та кількісна оцінка його короткочасного впливу на здоров'я населення.

Матеріали та методи. Вимірювання концентрацій озону в атмосферному повітрі м. Києва проводилося за допомогою газового аналізатора APOA 370 HORIBA протягом 3-х років з червня по серпень (2017-2019) у денний час (з 10:00 до 18:00). Отримані дані були співставлені з гранично допустимою концентрацією згідно з наказом МОЗ України № 52 від 14.01.2020 (ПДКм.р. - 0,16 мг/м³), міжнародними критеріями, встановленими Директивою 2008/50/ЄС (8-годинна

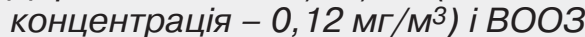

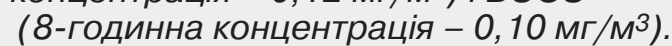
Для кількісної оцінки короткочасного впливу зареєстрованих концентрацій озону на здоров'я населення у 2017-2018 роках використовувався міжнародний програмний комплекс AirQ+.
Результати. Аналіз даних дозволив зробити висновок: рівні забруднення атмосферного повітря озоном у м. Києві перевищують граничні значення, рекомендовані гігієнічними нормативами України, а також Директивою 2008/50/ЄС та ВООЗ. Середні концентрації озону визначалися 2017 року на рівні $(0,20 \pm 0,03) \mathrm{Mr} / \mathrm{M}^{3} ; 2018$ p. - $(0,19 \pm$ $0,04) \mathrm{Mr} / \mathrm{M}^{3} ; 2019$ p. - $(0,18 \pm 0,05) \mathrm{Mr} / \mathrm{M}^{3}$. Максимальне перевищення спостерігалося у червні на рівні 1,4 ГДКм.р. 8-годинні концентрації озону перевищували міжнародні граничні значення, встановлені Директивою 2008/50/ЄС та ВОО3, у 97,0\% і 98,0\% випадків відповідно (максимально - у 2,7 рази). Кількість додаткових смертей на 100 тисяч населення становила 2017 р. (2018 р.) 65,39 $(62,65)$ випадків від хвороб системи кровообігу; 59,21 (56,87) - загальної смертності; 1,30 $(1,38)$ - хвороб органів дихання.

Висновок. Проведені дослідження доводять необхідність обов'язкового впровадження у систему моніторингу концентрацій озону у приземному шарі атмосферного повітря для оцінок масштабів людських втрат та інформування щодо можливих загроз громадському здоров'ю.

Ключові слова: атмосферне повітря, моніторинг, приземний озон, AirQ+.

() Турос O.І., Петросян А.A., Маремуха Т.П. СТАТТЯ, 2020. 
швидкої допомоги можна побічно визначати концентрації озону у повітрі. Наголошується, що збільшення концентрації озону на 20 мкг /м³ призводить до зростання смертності на 0,64\% від серцево-судинних захворювань і захворювань органів дихання [6]. У дослідженнях інших авторів [7] йдеться про збільшення смертності від серцево-судинних захворювань на $0,45 \%$ у разі підвищення часових концентрацій озону

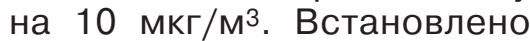
також, що за концентрації приземного озону на рівні

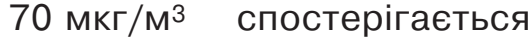
негативний вплив на здоров'я людини, який зумовлює збільшення додаткової смертності на 0,6\% [8]. Особливо вразливими до озону є діти. Це пов'язане з незрілістю їхньої ферментної, імунної та дихальної систем. Також діти більше часу проводять на відкритому повітрі, рівень їхньої активності вищий порівняно 3 дорослими, що призводить до збільшення концентрації забруднюючих речовин на одиницю площі легень [3].

3 метою досягнення Глобальних цілей розвитку, вимог $€ C$ щодо імплементації директив, рекомендацій ВООЗ виникає необхідність оцінки небезпеки, викликаної забрудненням атмосферного повітря озоном на території України. При цьому першочерговим завданням мають стати організація його спостереження у загальній системі державного моніторингу та опрацювання критеріїв їх нормування на підставі наявних наукових оцінок відповідно до Постанови КМУ № 827 «Деякі питання здійснення державного моніто- рингу у галузі охорони атмосферного повітря» від 14.08.2019 [9, 10].

Метою даної роботи було визначення та аналіз отриманих концентрацій озону в атмосферному повітрі м. Києва та кількісна оцінка його короткочасного впливу на здоров'я населення.

Матеріали та методи досліджень. Вимірювання концентрацій озону в атмосферному повітрі було проведене за допомогою газового аналізатора APOA 370 HORIBA. Оцінка вмісту озону здійснювалася методом недисперсійної ультрафіолетової абсорбції з перехресною модуляцією - NDUV у діапазоні вимірювань від 0 ррm до 0,1/0,2/0,5/1,0 ppm. Чутливість методу - для діапазону менше 0,2 ppm та 0,5 ppm $(2 \sigma)$, для діапазону більше

Таблиця 1

Середні концентрації озону в атмосферному повітрі м. Києва, 2017-2019 рр.

\begin{tabular}{|c|c|c|c|c|c|c|c|}
\hline \multirow{3}{*}{ Місяць } & \multicolumn{7}{|c|}{ Концентрація, мг/м³ } \\
\hline & \multicolumn{2}{|c|}{2017 рік } & \multicolumn{2}{|c|}{2018 рік } & \multicolumn{2}{|c|}{2019 рік } & \multirow{2}{*}{ ГДК } \\
\hline & $\mathrm{M} \pm$ & $\min -\max$ & $\mathrm{M} \pm$ & $\min -\max$ & $\mathrm{M} \pm$ & $\min -\max$ & \\
\hline Червень & $0,22 \pm 0,02$ & $0,13-0,28$ & $0,22 \pm 0,04$ & $0,12-0,34$ & $0,23 \pm 0,02$ & $0,11-0,31$ & 0,16 \\
\hline Липень & $0,20 \pm 0,03$ & $0,11-0,27$ & $0,17 \pm 0,02$ & $0,10-0,27$ & $0,16 \pm 0,04$ & $0,10-0,36$ & \\
\hline Серпень & $0,19 \pm 0,02$ & $0,10-0,26$ & $0,18 \pm 0,04$ & $0,10-0,27$ & $0,17 \pm 0,04$ & $0,11-0,31$ & \\
\hline
\end{tabular}

Середні 8-годинні концентрації озону в атмосферному повітрі, м. Київ (червень-серпень 2017-2019 рр.)

0,3

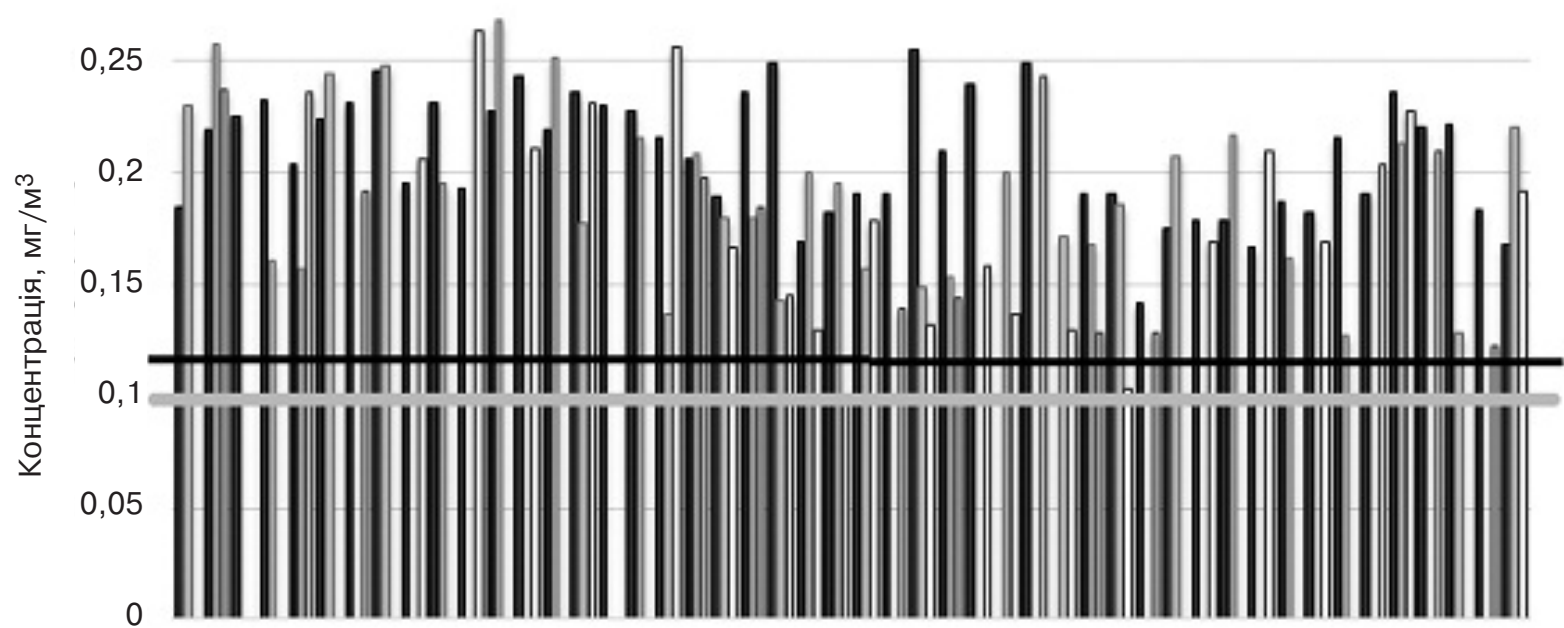

червень

липень

серпень

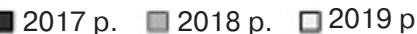

Граничні значення: - Директива 2008/50/ЄС $=$ ВООЗ 


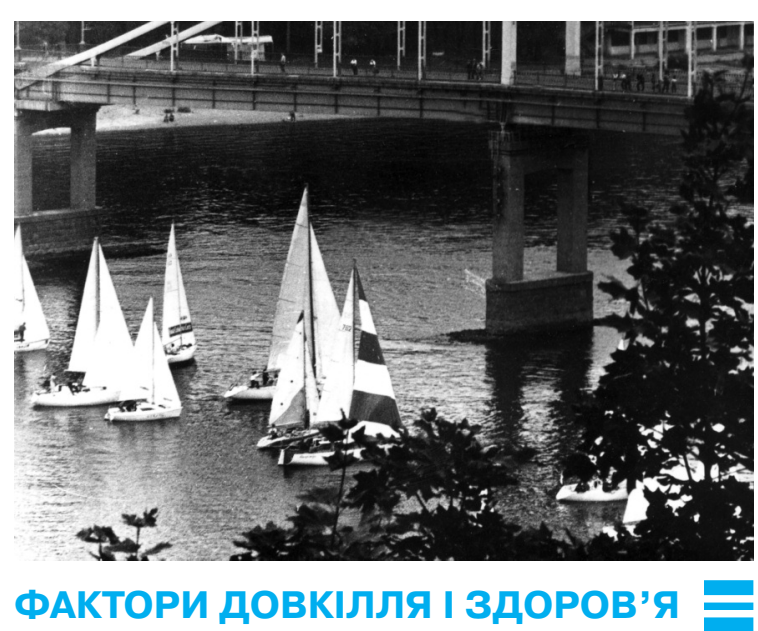

0,2 ppm - 0,5\% (2 б) повної довжини шкали.

Дослідження проводилися у м. Києві з червеня по серпень протягом 3-х років (2017-2019) у денний час протягом 8 годин (з 10:00 до 18:00). Усереднені значення 1- та 8-годинних концентрацій озону порівнювали 3 вітчизняним гігієнічним нормативом (ГДК клас небезпеки) та міжнародними критеріями ВООЗ (8годинне значення - 0,10 мг / $^{3}$ ) та Директиви 2008/50/€С (8-годинне значення - 0,12 мг $\left./ \mathrm{M}^{3}\right)[1,9,11]$.

Статистична обробка результатів вимірювань була проаналізована за допомогою інструментів Excel та програмного пакета STATISTICA (метод одномірної статистики обробки даних; середньоарифметична величина $\mathrm{M}_{\text {сер }}$, їі стандартне відхилення $-\sigma)$.

Оцінку наслідків для здоров'я, пов'язаних з короткочасним впливом озону влітку 2017-2018 років, здійснювали з використанням програмного комплексу AirQ+, що розроблений Європейським регіональним бюро ВООЗ. Усі розрахунки засновані на методології та функціях «експозиція - відповідь», встановлених у ході міжнародних епідеміологічних досліджень. Негативний вплив зареєстрованих концентрацій озону за конкретний період часу розраховувався з урахуванням відносного ризику та смертності певної популяції $[3,12]$.

у програмний комплекс AirQ+ вводилося значення SOMO35 (сума максимальних добових значень середнього показника концентрації за 8 годин, що перевищують

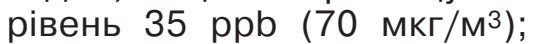
кількість днів, що використовувалися для розрахунку SOMO35; чисельність населення м. Києва та показники смертності (від хвороб органів дихання (J00-J99); хвороб системи кровообігу (100-199); загальна (А00-Ү98), за виключенням зовнішніх причин смерті (V01-Y98)) [12, 13]. Статистичну інформацію от- метеорологічними особливостями у даний період року в Україні [14]. Розраховані концентрації озону в атмосферному повітрі у 2017-20182019 роках перевищували діючий гігієнічний норматив в Україні і становили у червні 1,4 ГДК 1,0 ГДК К.р. у серпні - 1,2-1,11,1 ГДК м.р [11]. Загалом отримані 1-годинні концентрації озону перевищували 0,16 мг /M³ у 72,7\% випадків 2017 року, у 68,8\% - 2018 р., у $60,6 \%-2019 p$

8-годинне усереднення результатів інструментальних досліджень озону виявило перевищення граничних значень, встановлених Директивою 2008/50/€С $\left(0,12 \mathrm{Mr} / \mathrm{M}^{3}\right)$ та ВОO3 $\left(0,10 \mathrm{Mr} / \mathrm{M}^{3}\right)$ у $97,0 \%$ та 98,0\% випадків відповідно (максимальне перевищення - у 2,7 рази) (рис. 1). Відповідно до критеріальних оцінок ВООЗ такі рівні концентрацій озону істотно впливають на стан здоров'я населення, зумовлюючи більше додаткових випадків щоденних смертей на 3-5\% порівня-

Таблиця 2

\section{Вхідні дані для кількісної оцінки впливу озону на здоров'я населення м. Києва (червень-серпень 2017-2018)}

\begin{tabular}{|l|c|c|}
\hline \multicolumn{1}{|c|}{ Показник } & \multicolumn{2}{c|}{ Значення } \\
\cline { 2 - 3 } & 2017 р. & 2018 р. \\
\hline Чисельність населення & 2888834 & 2901364 \\
\hline $\begin{array}{l}\text { Смертність загальна А00-Ү98 (за винятком } \\
\text { зовнішніх причин смерті V01-Ү98)* }\end{array}$ & 1013,07 & 1058,78 \\
\hline Смертність від хвороб системи кровообігу I00-I99* & 676,5 & 704,05 \\
\hline Смертність від хвороб органів дихання J00-J99* & 22,32 & 25,64 \\
\hline SОМО35 (мкг/м³) & 9567 & 6101 \\
\hline $\begin{array}{l}\text { Кількість днів, що використовувалися } \\
\text { для розрахунку SОМО35 (мкг/м³) }\end{array}$ & 46 & 32 \\
\hline
\end{tabular}

Примітка: * показник на 100 тисяч населення.

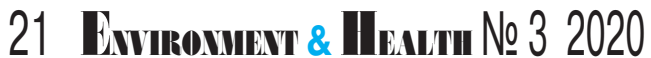


но зі смертністю за експозиції на розрахунковому фоновому рівні $[1,2]$.

у таблиці 2 наведено вхідні дані для розрахунків кількісної оцінки короткочасного впливу озону на здоров'я населення за допомогою AirQ+ [14].

У таблиці 3 представлено кількість атрибутивних випадків смерті (від загальних причин, хвороб системи кровообігу та органів дихання) у м. Києві, що зумовлена впливом озону у концентраціях, визначених влітку 2017-2018 рр.

Як видно з таблиці 3, за результатами розрахунків атрибутивні випадки смерті у м. Києві, віднесені до впливу

\section{Атрибутивні випадки смерті від короткострокового впливу озону на населення у м. Києві (червень-серпень 2017-2018 рр.)}

\begin{tabular}{|c|c|c|c|c|}
\hline $\begin{array}{l}\text { Критерій оцінки, } \\
\text { відносний ризик }\end{array}$ & Показник & Результат & 2017 p. & 2018 p. \\
\hline \multirow{4}{*}{$\begin{array}{l}\text { Загальна } \\
\text { смертність } \\
1,0029 \\
(1,0014-1,0043)\end{array}$} & \multirow{2}{*}{$\begin{array}{c}\text { атрибутивні } \\
\text { випадки }\end{array}$} & кількість & 1711 & 1650 \\
\hline & & $\mathrm{Cl}^{*}$ & 839-2499 & $809-2413$ \\
\hline & \multirow{2}{*}{$\begin{array}{c}\text { атрибутивне } \\
\text { співвідношення }\end{array}$} & $\%$ & 5,84 & 5,37 \\
\hline & & $\%(95 \mathrm{Cl})$ & $2,87-8,54$ & $2,63-7,85$ \\
\hline \multirow{4}{*}{$\begin{array}{l}\text { Смертність від } \\
\text { хвороб системи } \\
\text { кровообігу } \\
1,0049 \\
(1,0013-1,0085)\end{array}$} & \multirow{2}{*}{$\begin{array}{c}\text { атрибутивні } \\
\text { випадки }\end{array}$} & кількість & 1889 & 1818 \\
\hline & & $\mathrm{Cl}$ & $521-3154$ & $500-3044$ \\
\hline & \multirow{2}{*}{$\begin{array}{c}\text { атрибутивне } \\
\text { співвідношення }\end{array}$} & $\%$ & 9,67 & 8,9 \\
\hline & & $\%(95 \mathrm{Cl})$ & $2,67-16,14$ & $2,45-14,9$ \\
\hline \multirow{4}{*}{$\begin{array}{l}\text { Смертність від } \\
\text { хвороб органів } \\
\text { дихання } \\
1,0029 \\
(1-1,007)\end{array}$} & \multirow{2}{*}{$\begin{array}{c}\text { атрибутивні } \\
\text { випадки }\end{array}$} & кількість & 38 & 40 \\
\hline & & $\mathrm{Cl}$ & $0-87$ & $0-93$ \\
\hline & \multirow{2}{*}{$\begin{array}{c}\text { атрибутивне } \\
\text { співвідношення }\end{array}$} & $\%$ & 5,84 & 5,37 \\
\hline & & $\%(95 \mathrm{Cl})$ & $0,00-13,5$ & $0,00-12,45$ \\
\hline
\end{tabular}

Примітка: * $\mathrm{Cl}$ - довірчий інтервал.

Додаткова смертність на 100 тис. населення

Рисунок 2 від короткочасного впливу озону (червень-серпень 2017-2018 рр.)

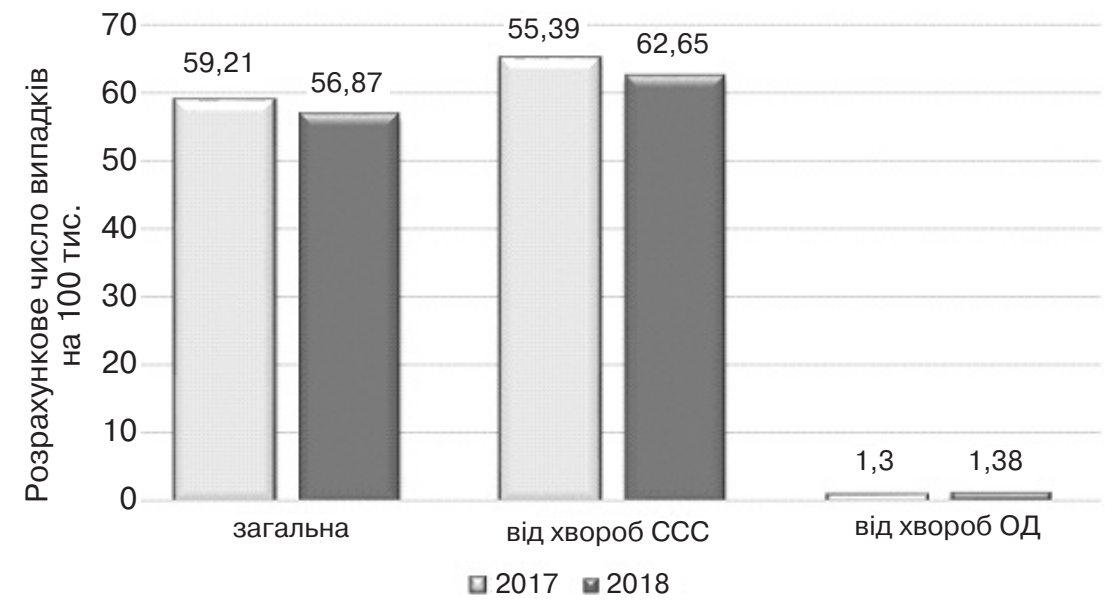

станням програмного комплексу AirQ+ свідчить, що значній кількості смертей можна було запобігти, якби рівень забруднюючої речовини відповідав критеріям оцінки ВООЗ [1].

Проведені дослідження доводять необхідність обов'язкового впровадження у систему моніторингу спостереження за концентраціями озону у приземному шарі атмосферного повітря для оцінок масштабів людських втрат та інформування щодо можливих загроз громадському здоров'ю.

\section{Висновки}

3 метою удосконалення, розробки та організації державної системи моніторингу якості атмосферного повітря в Україні, відповідно до вимог Директиви ЄС 2008/50/ЄС та Постанови КМУ № 827 від 14.08.2019, пропонується розширення моніторингових програм і включення до переліку пріоритетних забруднюючих речовин озону 3 обов'язковим контролем його вмісту в атмосферному повітрі населених місць.

Визначено, що рівні озону перевищували вітчизняний гігієнічний норматив, міжнародні критерії оцінки ВООЗ та Директиви 2008/50/€С, що зумовлює збільшення додаткових випадків смертей 3 загальних причин, хвороб системи кровообігу, органів дихання та потребує розробки профілактичних заходів у системі соціально-гігієнічного моніторингу.

ЛІТЕРАТУРА

1. Air quality guidelines global update 2005

Copenhagen : WHO Regional Office for Europe, 2006. 484 p.

2. Health risks of air pollution in Europe - HRAPIE : technical report. Copenhagen : WHO Regional Office for Europe, 2014. $65 \mathrm{p}$.

3. Review of evidence on health aspects of air pollution REVIHAAP : technical report. Copenhagen : WHO Regional Office for Europe, 2013. 302 p.

4. Gold D.R., Samet J.M. Air pollution, climate, and 
ASSESSMENT OF THE DAMAGE FOR THE HEALTH OF THE POPULATION FROM THE SHORT-TERM EXPOSURE TO THE HIGH OZONE CONCENTRATIONS Turos O.I., Petrosian A.A., Maremukha T.P. State Institution «O.M. Marzieiev Institute for Public Health, NAMS Ukraine», Kyiv

Objective: We peformed a hygienic assessment of the level of ambient air pollution with ozone in Kyiv and a quantitative assessment of its short-term impact on the health of the population.

Materials and methods: Measurement of ozone concentrations in the ambient air of Kyiv was carried out using a gas analyzer APOA 370 HORIBA in the daytime (from 10:00 to 18:00) from June to August (2017-2019) for 3 years. Obtained data were compared with the maximum permissible concentration according to the order of the Ministry of Health of Ukraine № 52, 01/14/2020 (MPC.m. - $0.16 \mathrm{mg} / \mathrm{m}^{3}$ ) and international criteria established by the Directive 2008/50/EC (8-hour concentration $0.12 \mathrm{mg} / \mathrm{m}^{3}$ ) and the WHO (8-hours concentration $-0.10 \mathrm{mg} / \mathrm{m}^{3}$ ). To quantify the impact of the short-term effects of ozone concentrations on public health in 2017-2018 we used the international software package AirQ+.
Results: Analysis of the data led to the conclusion that the levels of ozone air pollution in Kyiv exceeded the limit values recommended by the hygienic standards of Ukraine, as well as the Directive 2008/50/EC and the WHO. Average ozone concentrations were determined at the level of $(0.20 \pm 0.03) \mathrm{mg} / \mathrm{m}^{3}$ in 2017 ;

(0.19 \pm 0.04$) \mathrm{mg} / \mathrm{m}^{3}$ in 2018; $(0.18 \pm 0.05) \mathrm{mg} / \mathrm{m}^{3}$ in 2019. The maximum excess was observed in June at the level of $1.4 \mathrm{MPCm}$.s.

8-hours ozone concentrations exceeded the international limit values established by the Directive 2008/50/EC and the WHO in 97.0\% and $98.0 \%$ of cases, respectively (maximum 2.7 times). For 2017 (2018) the number of the additional deaths per 100 thousands of the population made up 65.39 (62.65) cases of the diseases of circulatory system; 59.21 (56.87) total mortality; 1.30 (1.38) - respiratory diseases.

Conclusion: Performed studies prove the need of mandatory implementation into the observation monitoring system for ozone in the surface layer of ambient air to assess the extent of human losses and to inform about possible threats to public health.

Keywords: atmospheric air, monitoring, surface ozone, AirQ+. heart disease. Circulation.

2013. Vol. 128.

P. 411-414.

5. State of Global Air 2018 : special report / Health Effects Institute. Boston, MA, 2018. 24 p.

6. Bates D.V. Ambient ozone and mortality. Epidemiology. 2005. Vol. 16 (4). P. 427-429.

7. Gryparis A., Forsberg B., Katsouyanni K., Analitis A., Touloumi G., Schwartz J. et. al. Acute Effects of Ozone on Mortality from the «Air Pollution and Health: A European Project Approach». Am. J. Respir. Crit. CareMed. 2004. Vol. 170.

P. 1080-1087.

8. Farraj A., Hazari M., Winsett D.W., Kulukulualani A., Carll A.P., Haykal-Coates N. et al. Overt and Latent Cardiac Effects of Ozone Inhalation in Rats: Evidence for Autonomic Modulation and Increased Myocardial Vulnerability. Environmental Health Perspectives. 2012. Vol. 120 (3). P. 348-354.

9. Directive 2008/50/EC of the European Parliament and of the Council of 21 May 2008 on Ambient Air Quality and Cleaner Air for Europe.
Official Journal of the European Union. 2008. Vol. 51. L 152. 44 p.

10. Деякі питання здійснення державного моніторингу у галузі охорони атмосферного повітря : Постанова Кабінету Міністрів України № 827 від 14.08.2019. URL : https://zakon.rada.gov.ua/law s/show/827-2019-

$\% D 0 \% B F \# T e x t$

11. Про затвердження гігієнічних регламентів допустимого вмісту хімічних і біологічних речовин в атмосферному повітрі населених місць : Наказ МОЗ України № 52 від 14.01.2020 р., зареєстровано у Міністерстві юстиції України за № 156/34439 від

10.02.2020. URL :

https://zakon.rada.gov.ua/law s/show/z0156-20\#Text12.

12. AirQ+: Key Features.

WHO Regional Office for Europe. URL: https://www. euro.who. int/_data/assets/ pdf_file/0007/309994/AirQ10 -Key-features. pdf?ua=1

13. Mudu P., Gapp C., Dunbar M. AirQ+ Example of Calculations. WHO Regional Office for Europe, 2018. 31 p.
14. Інформаційний банк даних «Статистика населення України». URL: http://database.ukrcensus.gov.ua/MULT/ Dialog/statfile_c.asp 15. Потемкин В.Л, Потемкина Т.Г., Гусева Е.А. Динамика атмосферного озона в условиях высокогорья. Вестник ИрГТУ. 2015. № 3. C. 93-98.

\section{REFERENCES}

1. Air Quality Guidelines Global Update 2005. Copenhagen : WHO Regional Office for Europe; 2006 : $484 \mathrm{p}$.

2. Health Risks of Air Pollution in Europe HRAPIE : Technical Report. Copenhagen : WHO Regional Office for Europe ; 2014. 65 p.

3. Review of Evidence on Health Aspects of Air Pollution - REVIHAAP : Technical Report. Copenhagen : WHO Regional Office for Europe ; $2013: 302$ p.

4. Gold D.R. and Samet J.M. Air Pollution, Climate, and Heart Disease. Circulation. $2013 ; 128: 411-414$.

5. Health Effects Institute. State of Global Air 2018 :

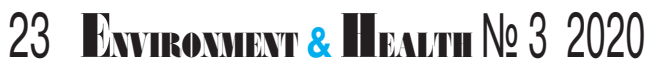


ОЦЕНКА УЩЕРБА ЗДОРОВЬЮ НАСЕЛЕНИЯ ОТ КРАТКОВРЕМЕННОГО ВОЗДЕЙСТВИЯ ВЫСОКИХ КОНЦЕНТРАЦИЙ ОЗОНА Турос Е.И., Петросян А.А., Маремуха Т.П. ГУ «Институт общественного здоровья им. А.Н. Марзеева НАМН Украины», Г. Киев

Цель работы - гигиеническая оценка уровня загрязнения атмосферного воздуха озоном в г. Киеве, количественная оценка его краткосрочного воздействия на здоровье населения.

Материалы и методы. Измерение концентраций озона в атмосферном воздухе г. Киева проводилось с помощью газового анализаTOpa APOA 370 HORIBA в течение 3-х лет с июня по август (2017-2019) в дневное время (с 10:00 до 18:00). Полученные данные были сопоставлены с предельно допустимой концентрацией согласно приказу МОЗ Украины № 52 от 14.01.2020 (ПДК международным критериям, установленным Директивой 2008/50/ЕС (8-часовая концентрация - 0,12 мГ/M $\left.\mathrm{M}^{3}\right)$ и ВОЗ (8-часовая концентрация - 0,10 мг/M33). Для количественной оценки влияния краткосрочного воздействия концентраций озона на здоровье населения в 2017-2018 годах использовался международный программный комплекс AirQ+.
Результаты. Анализ данных позволил сделать вывод: уровни загрязнения атмосферного воздуха озоном в Г. Киеве превышают предельные значения, рекомендованные гигиеническими нормативами Украины, а также Директивой 2008/50/EC и ВОЗ. Средние концентрации озона определялись В 2017 г. на уровне $(0,20 \pm 0,03) \mathrm{Mr} / \mathrm{M}^{3} ;$ в 2018 г. - $(0,19 \pm 0,04) \mathrm{Mr} / \mathrm{M}^{3} ;$ в 2019 г. - $(0,18 \pm 0,05)$ $\mathrm{Mr} / \mathrm{M}^{3}$. Максимальное превышение наблюдалось в июне: на уровне 1,4 ПДК м.р 8-часовые концентрации озона превышали международные предельные значения, установленные Директивой 2008/50/ЕС и ВОЗ, в 97,0\% и 98,0\% случаев соответственно (максимально - в 2,7 раза). Количество дополнительных смертей на 100 тысяч населения составляло в 2017 году (2018 г.): 65,39 $(62,65)$ случаев от болезней системы кровообращения; 59,21 (56,87) - общей смертности; $1,30(1,38)$ - болезней органов дыхания. Вывод. Проведенные исследования доказывают необходимость обязательного внедрения в систему мониторинга наблюдений за содержанием озона в приземном слое атмосферного воздуха для оценки масштабов человеческих потерь и информирование о возможных угрозах общественному здоровью.

Ключевые слова: атмосферный воздух, мониторинг, приземный озон, AirQ+.
Special Report. Boston, MA ; $2018: 24 \mathrm{p}$.

6. Bates D.V. Ambient Ozone and Mortality. Epidemiology. $2005 ; 16(4)$ : 427-429.

7. Gryparis A., Forsberg B., Katsouyanni K., Analitis A., Touloumi G., Schwartz J. et al. Acute Effects of Ozone on Mortality from the «Air Pollution and Health: A European Project Approach». Am. J. Respir. Crit. CareMed. 2004 ; 170 : 10801087.

8. Farraj A., Hazari M., Winsett D.W., Kulukulualani A., Carll A.P., Haykal-Coates N. et al. Overt and Latent Cardiac Effects of Ozone Inhalation in Rats: Evidence for Autonomic Modulation and Increased Myocardial Vulnerability. Environmental Health Perspectives. 2012 ; 120 (3) : 348-354.

9. Directive $2008 / 50 / E C$ of the European Parliament and of the Council of 21 May 2008 on Ambient Air Quality and Cleaner Air for Europe. Official Journal of the European Union. 2008 ; 51; L 152 : 44 p.
10. Deiaki pytannia zdiisnennia derzhavnoho monitorynhu v haluzi okhorony atmosfernoho povitria : Postanova KMU № 827 vid 14.08.2019 [Some Issues of State Monitoring in the Field of Air Protection: Resolution of the Cabinet of Ministers № 827, August 14, 2019]. URL :

https://zakon.rada.gov.ua/law s/show/827-2019-

$\% D 0 \% B F \# T e x t$ (in Ukrainian).

11. Pro zatverdzhennia hihiienichnykh rehlamentiv dopustymoho vmistu khimichnykh i biolohichnykh rechovyn $v$ atmosfernomu povitri naselenykh mists : Nakaz MOZ Ukrainy № 52 vid 14.01.2020. [On the Approval of the Hygienic Regulations of thePermissible Content of Chemical and Biological Substances in the Ambient Air of the Settlements: Order of the Ministry of Health of Ukraine № 52, 14.01.2020]. URL :

https://zakon.rada.gov.ua/law s/show/z0156-20\#Text (in Ukrainian).
12. AirQ+: Key Features. WHO Regional Office for Europe. URL:

https://www. euro.who.int/_da ta/assets/pdf_file/0007/30999 4/AirQ1-0-Key-

features. pdf?ua $=1$

13. Mudu P., Gapp C. and Dunbar M. AirQ+ Example of Calculations. WHO Regional Office for Europe ; $2018: 31 \mathrm{p}$. 14. Informatsiinyi bank danykh «Statystyka naselennia Ukrainy» [Information Database «Statistics of the Population of Ukraine»]. URL : http://database.ukrcensus.gov .ua/MULT/Dialog/statfile_c.as $p$ (in Ukrainian).

15. Potemkin V.L., Potemkina T.G. and Guseva E.A. Dinamika atmosfernogo ozona v usloviyakh vysokogoria [Dynamics of Atmospheric Ozone u under Conditions of Highland]. Vestnik Irkutskogo gosudarstvennogo tekhnicheskogo universiteta 2015. № 3. C. 93-98

(in Russian).

Надійшло до редакції 17.05.2020 